\title{
Quantifying is believing: Techniques for evaluating transthyretin cardiac amyloidosis burden for expanded clinical applications
}

\author{
Robert J. H. Miller, MD (D, ${ }^{a}$ and Nowell Fine, $M D, S M^{a}$ \\ a Libin Cardiovascular Institute and Department of Cardiac Sciences, University of Calgary, \\ Calgary, AB, Canada
}

Received Nov 15, 2021; accepted Nov 16, 2021

doi: $10.1007 / \mathrm{s} 12350-021-02880-8$

\section{See related article, pp. 3102-3110}

The clinical use of bone radiotracer imaging for the diagnosis of transthyretin cardiac amyloidosis (ATTR$\mathrm{CM}$ ) is growing exponentially. ${ }^{1,2}$ The combination of highly accurate non-invasive testing and targeted therapies which demonstrate clinical benefit, ${ }^{3,4}$ has created a perfect storm for increasing use and ongoing advancement of the technique. As a result, patients with less advanced disease are being referred for imaging including patients with identified genetic mutations during cascade screening without evidence of heart failure. ${ }^{5,6}$ With changing referral patterns, there has been increasing focus on the need to confirm diffuse myocardial radiotracer uptake on single photon emission computed tomography (SPECT) imaging to ensure accurate diagnosis. ${ }^{2,7}$ With the growing importance of SPECT, there have also been several efforts at quantifying radiotracer uptake from the images.

In this issue of the Journal of Nuclear Cardiology ${ }^{\circledR}$, Watanabe et al present one method for volumetric quantification of ${ }^{99} \mathrm{~m}$ technetium pyrophosphate $\left({ }^{99 \mathrm{~m}} \mathrm{Tc}\right.$ PYP) activity. ${ }^{8}$ The authors included 25 patients who underwent SPECT with computed tomography (CT) attenuation correction imaging. Using SPECT-CT images, cardiac pyrophosphate volume (CPV) was measured as the volume of ${ }^{99 \mathrm{~m}}$ Tc-PYP activity above a

Reprint requests: Robert J. H. Miller, MD, Libin Cardiovascular Institute and Department of Cardiac Sciences, University of Calgary, Calgary, AB, Canada; robert.miller@albertahealthservices.ca, robert.miller@ahs.ca

J Nucl Cardiol 2022;29:3111-4.

$1071-3581 / \$ 34.00$

Copyright (C) 2021 The Author(s) under exclusive licence to American Society of Nuclear Cardiology threshold established relative to aortic blood pool activity. The authors demonstrated high diagnostic accuracy for CPV using a threshold of $1.2 \times$ aortic blood pool activity $\left(\mathrm{CPV}_{1.2}\right)$, with area under the receiveroperating characteristic curve (AUC) of 0.96. AUC was numerically lower for CPV using a threshold of 1.4 (AUC 0.89) as well as heart contralateral lung (H/CL) ratio (AUC 0.91). A major strength of the study is that all patients underwent endomyocardial biopsy or had positive genetic testing (with other evidence of cardiomyopathy) to adjudicate a diagnosis of ATTR-CM. These promising results support the concept that quantification of bone radiotracer uptake is feasible and has high diagnostic accuracy for the detection of ATTRCM.

There are a few limitations to this study which should be acknowledged. ${ }^{8}$ The population sample was relatively small and as a result diagnostic accuracy was not statistically different between any of the proposed methods. ${ }^{8}$ Therefore, larger studies are needed to more conclusively demonstrate the high diagnostic accuracy of CPV. The proposed measurements are dependent on placement of volumes of interest, which could be subject to interobserver variability leading to some variability in measurements. However, our group described a similar method, using SPECT images, with low interobserver variability and excellent agreement on the presence of abnormal activity. ${ }^{9}$ This task would be simplified with the use of CT attenuation correction images to provide anatomic localization, making this limitation relatively minor. Lastly, the authors applied their analysis to images performed 3 hours post radiotracer injection, and additional studies are needed to determine if the proposed method, and threshold values for CPV, could be similarly applied to SPECT/CT imaging performed at 1 or 2-hours. ${ }^{10}$

There are now several methods which have been proposed to quantify bone radiotracer uptake from 
Table 1. Selected studies investigating quantitative single photon emission computed tomography image analysis

\begin{tabular}{|c|c|c|c|}
\hline Study & Isotope & Measurement & Results \\
\hline $\begin{array}{l}\text { Ramsay et al } \\
(2018)^{16}\end{array}$ & HMDP & $\mathrm{SUV}_{\max }$ & $\begin{array}{l}\text { Patients with ATTR-CM had higher SUV } V_{\max } \text { compared to patients } \\
\text { without ATTR-CM }\end{array}$ \\
\hline $\begin{array}{l}\text { Scully et al } \\
(2020)^{15}\end{array}$ & DPD & $\begin{array}{l}\text { SUV }_{\text {peak, }} \\
\text { SuV retention } \\
\text { index }\end{array}$ & $\begin{array}{l}\text { Diagnostic accuracy } 0.999 \text { for SUV } \\
\text { SUV }_{\text {peak }} \text { and SUV retention index. }\end{array}$ \\
\hline $\begin{array}{l}\text { Dorbala et al } \\
(2020)^{12}\end{array}$ & PYP & $\begin{array}{l}\text { SUV }_{\text {mean }}, \text { SUV }_{\max } \\
\text { CAA, \%ID }\end{array}$ & $\begin{array}{l}\text { All measures had diagnostic accuracy }>0.96 \text {. Moderate } \\
\text { correlations with LVMI }\left(r^{2}=0.105-0.235\right) \text { and good } \\
\text { correlations with ECV by CMR }\left(r^{2}=0.619-0.762\right)\end{array}$ \\
\hline $\begin{array}{l}\text { Ben Haim } \\
\text { et al } \\
(2021)^{13}\end{array}$ & DPD & $\begin{array}{l}\mathrm{SUV}_{\text {max }}, \text { SUV }_{\text {mean }} \\
\text { above threshold }\end{array}$ & $\begin{array}{l}\text { Both methods had perfect accuracy for distinguishing grade } 0 \\
\text { uptake. One patient with AL had abnormal quantitation. }\end{array}$ \\
\hline $\begin{array}{l}\text { Miller et al } \\
\quad(2021)^{9}\end{array}$ & PYP & VOI, CPA & $\begin{array}{l}\text { CPA and VOI had diagnostic accuracy of } 0.996 \text {. Moderate } \\
\text { correlations with LVEF }\left(r^{2}=0.176\right) \text {. Associated with heart } \\
\text { failure hospitalizations }\end{array}$ \\
\hline $\begin{array}{l}\text { Ren et al } \\
\qquad(2021)^{14}\end{array}$ & PYP & SuV $_{\max }$ & $\begin{array}{l}\text { SUV }_{\text {max }} \text { significantly higher in patients with ATTR-CM compared } \\
\text { to AL. Higher SUV } \\
\text { max with increasing planar grade }\end{array}$ \\
\hline $\begin{array}{l}\text { Roshankar } \\
\text { et al } \\
(2021)^{11}\end{array}$ & PYP & VOI, CPA & $\begin{array}{l}\text { Moderate correlations with native T1 }\left(r^{2}=0.502-0.617\right) \text { and } \\
\text { ECV by CMR }\left(r^{2}=0.515\right) \text {. Associated with heart failure } \\
\text { hospitalization or cardiovascular death. }\end{array}$ \\
\hline $\begin{array}{l}\text { Watanabe } \\
\text { et al } \\
(2021)^{8}\end{array}$ & PYP & $\begin{array}{l}\mathrm{SUV}_{\max }, \mathrm{CPV} \\
\mathrm{CPV}_{1.4}\end{array}$ & $\begin{array}{l}\text { Diagnostic accuracy } 0.96 \text { for } \mathrm{CPV}_{1.2} \text { and } 0.89 \text { for } \mathrm{CPV}_{1.4 \cdot} \\
\text { Moderate correlations with LVEF }\left(r^{2}=0.36\right) \text { and LVPWTd } \\
\left(r^{2}=0.46\right)\end{array}$ \\
\hline
\end{tabular}

$C A A$, cardiac amyloid activity, $C M R$, cardiovascular magnetic resonance, $C P A$, cardiac pyrophosphate activity, $C P V$, cardiac pyrophosphate volume, $C T$, computed tomography, $D P D, 3,3$-diphosphono-1,2-propanodicarboxylic acid, $E C V$, extracellular volume, $H M D P$, hydroxymethylene diphosphonate, $L V E F$, left ventricular ejection fraction, $L V P W T d$, left ventricular posterior wall thickness at end-diastole, PYP, pyrophosphate, SUV, standardized uptake value, $V O I$, volume of involvement

SPECT imaging. ${ }^{8,9,11-16}$ A few of these studies are outlined in Table 1. Some methods are based on measuring maximal standardized uptake volumes $\left(\mathrm{SUV}_{\max }\right)$. However, there may be some inaccuracy to $\mathrm{SUV}_{\max }$ measurements with SPECT compared to positron emission tomography due to lower spatial resolution and partial volume effects. ${ }^{17}$ Other efforts, like the one proposed by Watanabe et al, are based on volumetric measurements. Volumetric measurements quantify either volume of activity above a threshold or attempt to quantify both volume and intensity of abnormal activity. Volumetric measurements are potentially subject to interobserver variability related to region of interest placement. Regardless, studies consistently demonstrate high diagnostic accuracy for these techniques with AUCs ranging from 0.96 to 0.999 . The minor variations in AUC are most likely related to differences in referral patterns among these largely single center studies, and it is unlikely that one superior measure could be established on the basis of diagnostic accuracy alone. In fact, visual interpretation of SPECT seems to be the optimal method for disease diagnosis since it has similarly high diagnostic accuracy compared to these quantitative approaches and is substantially simpler to perform.

In the absence of differences in diagnostic accuracy, it is necessary to consider the larger potential clinical application and utility to determine which one measurement has the greatest efficacy. Quantitative assessment of bone radiotracer uptake could potentially be used to non-invasively stage severity of disease, estimate risk of cardiovascular events, or assess response to therapy. Correlations with other measures of disease severity may be helpful in establishing these clinical roles. Watanabe et al demonstrated correlations between $\mathrm{CPV}$ and left ventricular ejection fraction. We demonstrated that cardiac pyrophosphate activity (CPA) was correlated with left ventricular hypertrophy and left ventricular ejection fraction. ${ }^{9}$ More recently we demonstrated that CPA was also correlated with burden of late gadolinium enhancement and native myocardial 
T1 using cardiovascular magnetic resonance (CMR) imaging. ${ }^{11}$ Dorbala et al demonstrated significant correlations with extracellular volume estimates from CMR. ${ }^{12}$ Many of the previously discussed studies have also demonstrated associations with clinical outcomes; however, the patient sample sizes preclude making firm conclusions based on these results. Overall, these studies provide some confidence that these measures may be useful for assessing disease burden non-invasively.

Ultimately, beyond accurate diagnosis, the most important question is whether quantitative methods can be used clinically to alter patient management and improve patient outcomes. Given the significant cost associated with novel disease-modifying therapies for ATTR-CM ${ }^{18}$ methods to identify patients most likely to benefit could improve selection criteria, decreasing costs and improving patient outcomes. Alternatively, quantitative imaging could be used to determine response to therapy, an important knowledge gap in clinical practice. ${ }^{19}$ Fontana et al demonstrated that quantification of SPECT/CT images, using measurement of precent injected dose, decreased over time in a cohort of 16 patients with hereditary ATTR-CM treated with Patisiran. ${ }^{20}$ Therefore, these techniques may be able to help identify patients who are not responding and could be switched to an alternative agent earlier before the onset of irreversible organ damage. Given the rate of progress in the field of nuclear imaging for ATTR-CM, it's likely that one or more of these clinical roles will become more established in the near future.

\section{Disclosure}

Dr. Miller reports consulting support from Alnylam and Pfizer and research support from Pfizer. Dr. Fine reports research and consulting support from Pfizer, Akcea, Ionis, Alnylam, and Eidos.

\section{References}

1. Bokhari S, Morgenstern R, Weinberg R, Kinkhabwala M, Panagiotou D, Castano A. Standardization of (99m)Technetium pyrophosphate imaging methodology to diagnose TTR cardiac amyloidosis. J Nucl Cardiol 2018;25:181-90.

2. Poterucha TJ, Elias P, Bokhari S, Einstein AJ, DeLuca A, Kinkhabwala M, et al. Diagnosing transthyretin cardiac amyloidosis by technetium Tc $99 \mathrm{~m}$ pyrophosphate. JACC Cardiovasc Imaging 2021;14:1221-31.

3. Maurer MS, Schwartz JH, Gundapaneni B, Elliott PM, Merlini G, Waddington-Cruz $\mathrm{M}$, et al. Tafamidis treatment for patients with transthyretin amyloid cardiomyopathy. N Engl J Med 2018;379:1007-16.

4. Solomon SD, Adams D, Kristen A, Grogan M, González-Duarte A, Maurer MS, et al. Effects of patisiran, an RNA interference therapeutic, on cardiac parameters in patients with hereditary transthyretin-mediated amyloidosis. Circulation 2019;139:431-43.

5. Fine NM, Davis MK, Anderson K, Delgado DH, Giraldeau G, Kitchlu A, et al. Canadian Cardiovascular Society/Canadian Heart Failure Society joint position statement on the evaluation and management of patients with cardiac amyloidosis. Can J Cardiol 2020;36:322-34.

6. Witteles RM, Bokhari S, Damy T, Elliott PM, Falk RH, Fine NM, et al. Screening for transthyretin amyloid cardiomyopathy in everyday practice. JACC Heart Fail 2019;7:709-16.

7. Dorbala S, Ando Y, Bokhari S, Dispenzieri A, Falk RH, Ferrari VA, et al. ASNC/AHA/ASE/EANM/HFSA/ISA/SCMR/SNMMI expert consensus recommendations for multimodality imaging in cardiac amyloidosis: Evidence base and standardized methods of imaging. Circ Cardiovasc Imaging 2021;14:e000029.

8. Watanabe S, Nakajima K, Hiroshi W, Yoneyama H, Yoshida S, Komatsu J, et al. Volumetric evaluation of $99 \mathrm{mTc}$-pyrophosphate SPECT/CT for transthyretin cardiac amyloidosis: methodology and correlation with cardiac functional parameters. J Nucl Cardiol 2021;62:137.

9. Miller RJH, Cadet S, Mah D, Pournazari P, Chan D, Fine NM, et al. Diagnostic and prognostic value of Technetium-99m pyrophosphate uptake quantitation for transthyretin cardiac amyloidosis. J Nucl Cardiol 2021. https://doi.org/10.1007/s12350-02102563-4.

10. Sperry BW, Burgett E, Bybee KA, McGhie AI, O'Keefe JH, Saeed IM, et al. Technetium pyrophosphate nuclear scintigraphy for cardiac amyloidosis: Imaging at 1 vs 3 hours and planar vs SPECT/CT. J Nucl Cardiol 2020;27:1802-7.

11. Roshankar G, White GC, Cadet S, Fine NM, Chan D, White JA, et al. Quantitative technetium pyrophosphate and cardiovascular magnetic resonance in patients with suspected cardiac amyloidosis. J Nucl Cardiol 2021. https://doi.org/10.1007/s12350-02102806-4.

12. Dorbala S, Park MA, Cuddy S, Singh V, Sullivan K, Kim S, et al. Absolute quantitation of cardiac $(99 \mathrm{~m}) \mathrm{Tc}$-pyrophosphate using cadmium-zinc-telluride-based SPECT/CT. J Nucl Med 2021;62:716-22.

13. Ben-Haim S, Chicheportiche A, Goshen E, Arad M, Smekhov M, Menezes LJ, et al. Quantitative SPECT/CT parameters of myocardial 99mTechnetium-3,3-diphosphono-1,2-propanodicarboxylic acid (DPD) uptake in suspected cardiac transthyretin amyloidosis. EJNMMI Res 2021;11:86.

14. Ren C, Ren J, Tian Z, Du Y, Hao Z, Zhang Z, et al. Assessment of cardiac amyloidosis with $(99 \mathrm{~m}) \mathrm{Tc}$-pyrophosphate (PYP) quantitative SPECT. EJNMMI Phys 2021. https://doi.org/10.1186/ s40658-020-00342-7.

15. Scully PR, Morris E, Patel KP, Treibel TA, Burniston M, Klotz E, et al. DPD quantification in cardiac amyloidosis: A novel imaging biomarker. JACC Cardiovasc Imaging 2020;13:1353-63.

16. Ramsay SC, Lindsay K, Fong W, Patford S, Younger J, Atherton J. Tc-HDP quantitative SPECT/CT in transthyretin cardiac amyloid and the development of a reference interval for myocardial uptake in the non-affected population. Eur J Hybrid Imaging 2018;2:17.

17. Bailey DL, Willowson KP. An evidence-based review of quantitative SPECT imaging and potential clinical applications. J Nucl Med 2013;54:83-9.

18. Kazi DS, Bellows BK, Baron SJ, Shen C, Cohen DJ, Spertus JA, et al. Cost-effectiveness of tafamidis therapy for transthyretin amyloid cardiomyopathy. Circulation 2020;141:1214-24.

19. Garcia-Pavia P, Rapezzi C, Adler Y, Arad M, Basso C, Brucato A, et al. Diagnosis and treatment of cardiac amyloidosis. A position statement of the European Society of Cardiology Working Group 
on myocardial and pericardial diseases. Eur $\mathrm{J}$ Heart Fail 2021;23:512-26.

20. Fontana M, Martinez-Naharro A, Chacko L, Rowczenio D, Gilbertson JA, Whelan CJ, et al. Reduction in CMR derived extracellular volume with patisiran indicates cardiac amyloid regression. JACC Cardiovasc Imaging 2021;14:189-99.
Publisher's Note Springer Nature remains neutral with regard to jurisdictional claims in published maps and institutional affiliations. 